\title{
Planejamento urbano com uso de sistema de informação geográfica: o caso de Feira de Santana, BA.
}

\section{Urban Planning using geographic information system (SIG): the case of Feira de} Santana, $B A$.

Clarissa Figueiredo Sampaio Freitas ${ }^{1}$ Viridiana Gabriel Gomes² Marcos Borges ${ }^{3}$
1 Doutora em Arquitetura e Urbanismo pela FAU/UNB, foi professora do curso de Arquitetura e Urbanismo do UniCEUB no período de 2003 a 2009. Atualmente é professora adjunta do Departamento de Arquitetura e Urbanismo da Universidade Federal do Ceará.

2 Doutoranda em Arquitetura e Urbanismo pela FAU/UNB e professora do UniCEUB desde 2002.

3 Arquiteto, consultor da empresa PRISMA Consultoria.

\section{Resumo}

$\mathrm{O}$ artigo destaca o papel do acesso às informações que retratem com precisão as tendências da ocupação do território urbano no processo de elaboração de planos diretores municipais. Argumenta-se que, sem acesso às informações de boa qualidade, a eficiência das regulamentações territoriais fica comprometida devido à falta de conexão com a dinâmica urbana na qual se pretende intervir. $O$ cenário de imprecisão a respeito da dinâmica urbana acaba por dificultar o cumprimento das diretrizes de inclusão socioespacial previstas na legislação urbana federal. No sentido de discutir essa questão, o artigo apresenta o Sistema de Informações Geográficas como uma ferramenta capaz de ampliar o conhecimento a respeito do objeto urbano, ilustrando-o com o caso do município de Feira de Santana, na Bahia. Em última análise, entendemos que a maior contribuição do trabalho está no estabelecimento de uma metodologia de análise espacial das informações com a finalidade de apoiar o processo de planejamento urbano.

Palavras-chaves: Visualização da Informação. SIG. Planejamento urbano. Expansão Urbana.

\begin{abstract}
This paper highlights the role of access to data about the urban dynamics and future land use trends to inform the elaboration of municipal master plans in Brazil. We argue that the lack of access to high quality information jeopardize the efficacy of the master plans and their land use regulations. That is so because the decision about land use regulations must be informed by a good understanding of the urban dynamic affected. Without meeting such condition, the scenario of imprecision regarding the urban dynamics will not contribute to meet the national urban guidelines pertaining to socio-spatial inclusion. In order to pursue such question, the paper presents the Geographic Information System (GIS) as a tool capable of enhancing our understanding of the city. We do so by using the case of Feira de Santana, a medium sized city at Bahia, with some serious issues related to lack of urban information. By presenting the case, we understand that the main contribution of the paper relies in its spatial analysis methods, developed to inform the urban planning decision-making process.
\end{abstract}

Keywords: Data Visualization. GIS. Urban Planning. Urban Sprawl. 


\section{Introdução}

Com as mudanças na política urbana brasileira a partir da aprovação do Estatuto da Cidade (Lei no 10257/2001), muitos municípios foram obrigados a rever seus planos diretores, no sentido de adequá-los às diretrizes nacionais. Durante esse processo, a literatura aponta como dificuldades recorrentes, a ausência de estrutura administrativa adequada para o exercício do planejamento urbano e a baixa difusão de instrumentos de participação e controle social (SANTOS JUNIOR; MONTANDON, 2011). Esses fatores, aliados à nossa cultura política que não valoriza ações de planejamento e premia com ganhos eleitorais projetos pontuais (SOUZA, 2004; CAMPOS FILHO, 1999), seriam responsáveis pela pouca efetividade dos atuais dispositivos de planejamentos urbanos municipais. O presente artigo destaca um fator que costuma ser pouco mencionado pelos pesquisadores desse ramo de conhecimento: o papel do acesso às informações territoriais que retratem com precisão a dinâmica da ocupação do território urbano.

O Estatuto da Cidade traz uma série de instrumentos que foram elaborados com o objetivo de minimizar problemas urbanos recorrentes relacionados a um modelo de urbanização excludente. Tais instrumentos, como o IPTU progressivo, o solo criado e a transferência do direito de construir seriam aplicados pelos municípios para conter o processo de valorização imobiliária especulativa e a consequente exclusão da população de baixa renda do espaço efetivamente urbanizado. A aplicação de tais instrumentos é um desafio para os municípios tendo em vista que eles requerem uma base de informações territoriais sistematizadas e pessoal capacitado a manipulála, condição que poucos municípios brasileiros possuem.

Para Souza (2004), os instrumentos do Estatuto da Cidade são relativamente sofisticados se comparados aos instrumentos tradicionalmente utilizados no planejamento territorial, tais como o IPTU, o controle da aplicação dos parâmetros urbanísticos de taxas de ocupação, os índices de aproveitamento e afastamentos. $\mathrm{O}$ autor chama atenção para essa questão, sugerindo que gestores urbanos não desviem o foco para a aplicação de instrumentos muito sofisticados, enquanto o básico ainda não está sendo efetivado. De fato, a mera aplicação dos instrumentos tradicionais - como um cadastro territorial e a planta de valores das propriedades urbanas - já requer a existência de uma base de informações geográficas atualizada, condição que poucos municípios brasileiros atingem. A grande maioria das administrações municipais, incluindo municípios de grande porte como Fortaleza, trabalha com plantas de valores e bases cartográficas desatualizadas, que não refletem a dinâmica imobiliária da cidade.

Tal quadro de desinformação traz grandes limitações para o planejamento e gestão do território. Nesse sentido, é esclarecedora a afirmação de Pereira e Silva (2001, p. 105). Para eles, o papel principal da informação geográfica é o de

[...] reduzir a incerteza do nosso entendimento sobre o ambiente em que vivemos. A decisão em atividades de gestão e planejamento urbano ou regional requer conhecimento sobre o ambiente e, como este conhecimento não pode ser completo, as decisões são tomadas baseadas em informações incompletas.

Ou seja, a eficiência nas decisões de planejamento é função de uma base de informações que retrate com relativa precisão o ambiente construído. Tendo em vista que a maior parte das decisões tomadas pelo planejamento e gestão urbana possui um componente espacial importante, o mapeamento das informações torna-se fundamental, pois permite uma maior cognição por parte do gestor urbano.

Dessa forma, os Sistemas de Informações Geográficas (SIG) têm tido utilização crescente pelas administrações municipais e demais atores envolvidos com o planejamento do território, no sentido de aprimorar o processo de tomada de decisões. Os SIGs possuem a vantagem de permitir manipular, com relativa rapidez, uma grande quantidade de informações a respeito da dinâmica da ocupação territorial intraurbana, além de ser capaz de sobrepor dados de diversas fontes. A utilização de tais sistemas tem sido incentivada pelo Ministério das Cidades, que desenvolve atividades de capacitação dos técnicos das administrações municipais em softwares de SIG e rotinas de criação de cadastros multifinalitários. O Ministério desenvolve ainda publicações que orientam os municípios a elaborarem mapeamentos temáticos específicos, como os diagnósticos dos assentamentos precários (BRASIL, 2007; CUNHA; ERBA, 2010).

De forma a destacar o papel da utilização dos Sistemas de Informações Geográficas para a eficiência dos mecanismos de planejamento urbano, apresentaremos a seguir o caso de Feira de Santana. A escolha desse caso se deve à participação de alguns dos autores na elabora- 
ção de um relatório técnico intitulado "Estudos e projetos básicos de engenharia para a implantação da $2^{\mathrm{a}}$ etapa do programa de integração urbana de Feira de Santana", contratado pela Prefeitura Municipal de Feira de Santana durante o período de dezembro de 2010 a agosto de 2011. Parte desse relatório consistiu na elaboração de um SIG com o objetivo de retratar a dinâmica intraurbana do município. Para fins deste artigo, o sistema elaborado será utilizado como estudo de caso com o objetivo de discutir o papel do acesso às informações territoriais como apoio ao processo de planejamento urbano. No caso estudado, as principais fontes de informação foram: a Prefeitura Municipal, a Companhia de Abastecimento de Água local (EMBASA) e o IBGE.

O artigo organiza-se a partir da seguinte estrutura: na primeira parte identificamos os objetivos socialmente aceitos para o planejamento da expansão urbana da cidade a partir de análises documentais das legislações urbanísticas. Relacionaremos os insucessos no cumprimento de objetivos das legislações urbanas com um quadro de desinformação espacial e descontrole urbanístico presente na administração municipal. Em seguida, discutiremos as alterações na distribuição populacional intraurbana $\mathrm{e}$ da qualidade ambiental urbana nas duas ultimas décadas, a partir de dados censitários. Após olhar para o histórico da ocupação urbana e para o sistema de planejamento vigente, passamos a analisar o cenário futuro a partir de mapeamentos dos dados dos condomínios e loteamentos em fase de instalação.

\section{0 planejamento urbano de Feira de Santana e o quadro de desinformação territorial}

Feira de Santana é um município da Bahia localizado a $107 \mathrm{~km}$ a norte da capital Salvador. Sua mancha urbana se desenvolve a partir do entroncamento rodoviário da BR 116 e da BR 324, um cruzamento de grande importância na malha rodoviária nacional. Com o objetivo de evitar conflitos entre a malha rodoviária e o trânsito urbano, foi construído um anel de contorno, desviando o traçado da rodovia do centro da cidade.

Figura 1 - Planta de Localização da cidade de Feira de Santana

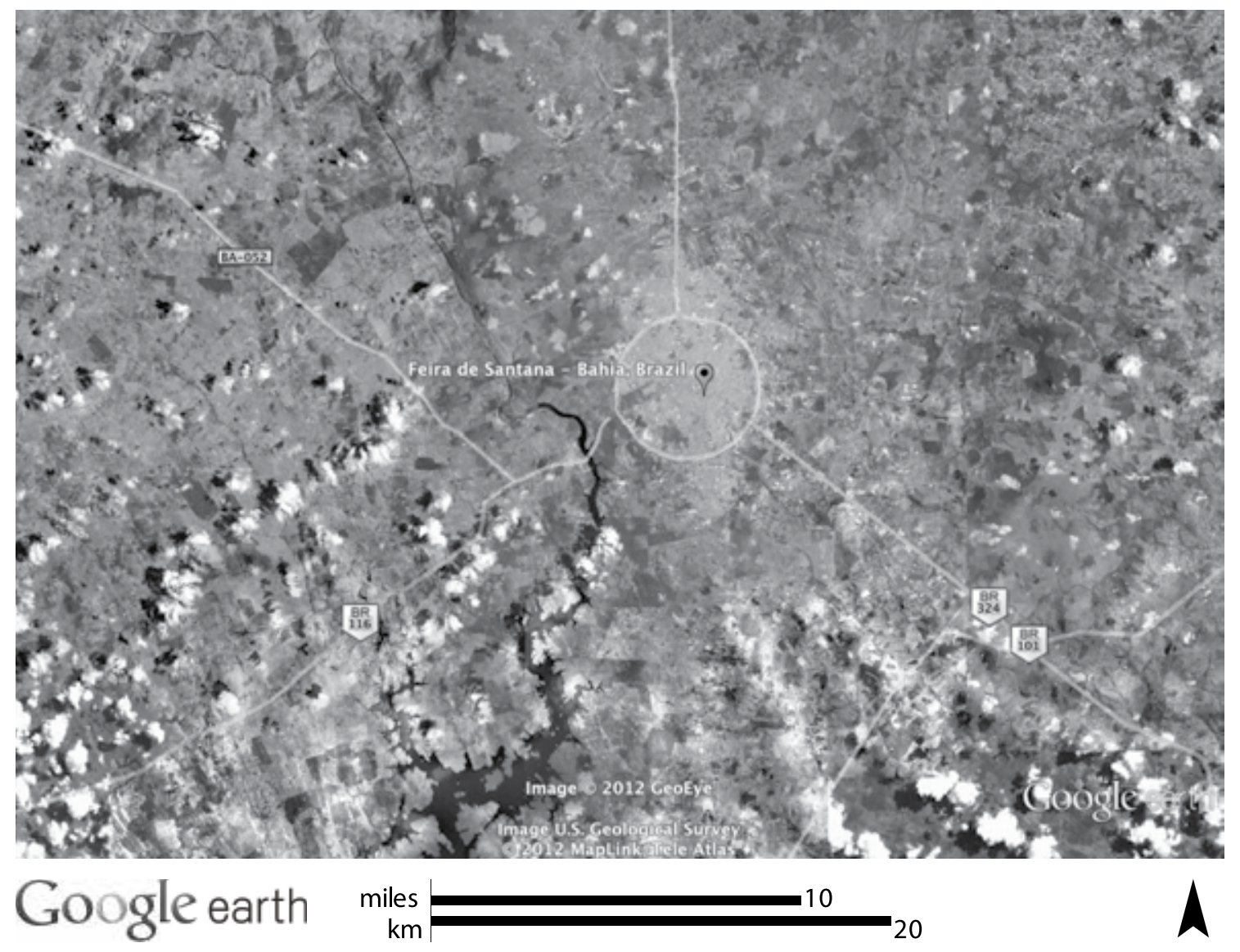


O Sistema de Planejamento Urbano de Feira de Santana atualmente em vigor iniciou-se em 1992 com a aprovação do Plano Diretor 1.1614 de 1992 e a Lei de Uso e Ocupação do Solo n ${ }^{\circ} 1.1615$ de 1992. Tais dispositivos definem como principal diretriz o estímulo ao adensamento populacional na zona interna ao anel construído para desviar o trânsito de passagem. Posteriormente, na ocasião da elaboração de propostas de atualização do Plano de 1992, a contenção do tecido urbano de Feira de Santana no interior do anel de contorno continua presente como um dos principais objetivos do planejamento urbano.

Nos dias atuais, qualquer usuário da cidade percebe a falha do planejamento no que se refere ao cumprimento de tal diretriz. De fato, vários dispositivos previstos pelo Sistema de Planejamento de 1992 não foram efetivados e a cidade apresenta um alto grau de irregularidade urbanística. Essa situação pode ser explicada de várias formas, já mencionadas na introdução deste artigo, todas relacionadas à pequena tradição de planejamento urbano da sociedade brasileira.

Um aspecto específico que será destacado aqui se refere à questão das dificuldades relativas ao acesso à informação territorial. De fato, o espraiamento da mancha urbana para além dos limites do anel de contorno pode ser explicado, em grande medida, pelo descontrole das sucessivas administrações municipais no que se refere ao seu desenvolvimento territorial.

Apesar de se tratar de um município de grande porte, Feira de Santana apresenta um quadro de desinformação no que se refere à dinâmica territorial urbana comparável a municípios de pequeno porte. A base cartográfica utilizada pela Secretaria de Planejamento $\mathrm{Mu}$ nicipal data de 1998. Mais grave que a desatualização dessa base é o fato de que ela não possui informações relativas à divisa de lotes ou contornos de edificações, resumindo-se ao sistema viário e aos contornos das quadras.

No setor de controle urbanístico, poucos funcionários possuem cópias das leis que estabelecem os parâmetros urbanísticos. Essa dificuldade de acesso à norma deve-se em grande medida ao formato da legislação: sua apresentação em formato $\mathrm{A} 3$ dificulta a reprodução. Outra dificuldade refere-se ao fato de que os loteamentos e os condomínios aprovados pela pre- feitura não estão localizados na base cartográfica oficial da cidade. Tal situação, não apenas limita a atividade de controle urbanístico, mas também impede a antecipação de problemas, característica essencial da atividade de planejamento urbano.

Esse quadro de obscuridade, no que se refere à informação espacial, abre espaço para a aprovação de leis que contradizem diretamente os objetivos de interesse público estabelecidos, sem que sejam apresentadas justificativas. Pode-se citar como exemplo a Lei Complementar no 45 de 2010. Tal lei amplia uma das zonas urbanas estabelecidas em 1992 (a ZR-4) na direção leste até os limites municipais. Tal alteração constitui um aumento disfarçado do perímetro urbano extrapolando em muito o polígono definido em 1992, que já ultrapassava o anel de contorno. Como os limites das zonas não são de fácil apropriação pela população urbana, sua alteração não requer justificativas por parte do proponente.

O dispositivo legal citado constitui um caso em uma série de legislações que alteram o sistema de planejamento definido em 1992, de forma desconectada com as diretrizes estabelecidas no plano diretor. Embora algumas dessas alterações mencionem instrumentos do Estatuto da Cidade - lei federal que estabelece as diretrizes para a política urbana dos municípios, aprovada em 2001 -, não se pode dizer que essas alterações compreendem uma revisão do Plano Diretor de 1992, conforme prevê a legislação federal. Trata-se de alterações pontuais para cumprir objetivos específicos, como alterações de parâmetros de uso e ocupação para determinados terrenos, viabilização do programa "Minha Casa, Minha Vida”, ou alteração nos limites das Zonas.

Apesar das inúmeras alterações nos dispositivos do Plano Diretor de 1992, e da aprovação de dispositivos que contradizem o objetivo de controle do espraiamento, esse objetivo continua presente no discurso político local. Isso se deve, em grande parte, à ausência de estudos técnicos que comprovem a existência de uma dissociação entre o objetivo do planejamento urbano e as medidas concretas de gestão da cidade que induzem a uma dinâmica urbana desconectada do objetivo do planejamento. Com apoio do Sistema de Informações Geográficas, as próximas seções buscam subsidiar essa questão, debruçando-se sobre a distribuição da população e da qualidade da urbanização no espaço intraurbano. 


\section{Distribuição da população e da qualidade da urbanização no espaço intraurbano}

O município de Feira de Santana possui 556.756 habitantes em 2010, sendo que destes, 510.736 (92\%) habitam a zona urbana. Esse dado recente representa um pequeno aumento na taxa de urbanização do município se comparado àquele do ano de 2000 , quando pouco menos de $90 \%$ dos 480.949 habitantes moravam na zona urbana.

$\mathrm{Na}$ escala intraurbana, os dados do censo 2000 já revelam a continuação do fenômeno de esvaziamento populacional na área central e nos bairros adjacentes localizados na porção interna ao anel de contorno. Se em 1996, 56\% da população urbana ainda habitava a área circundada pelo anel de contorno, apenas quatro anos depois esse percentual cai para $54 \%$, caindo para apenas $49 \%$ em 2010.

Figura 2 - Taxa de crescimento populacional por bairros

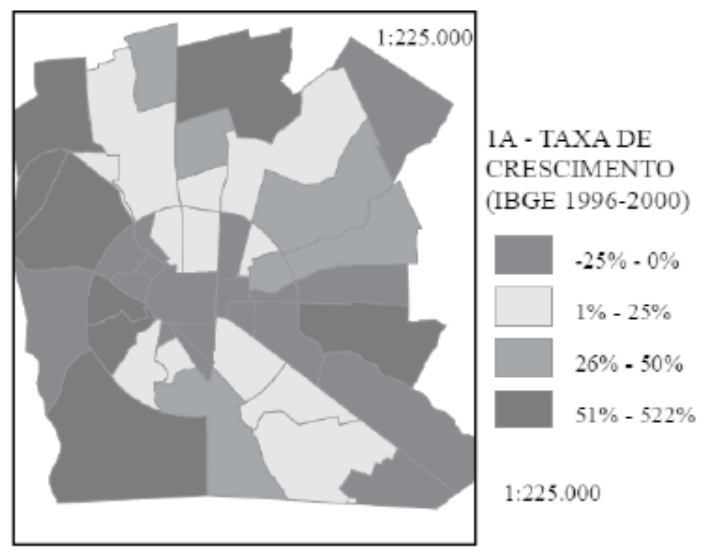

Entretanto, no período de 1991 a 2000, nota-se um incremento populacional em determinados bairros internos ao anel, mas ele se dá de forma localizada e não atinge os bairros com melhores indicadores de serviços urbanos. A Figura 2 revela que os bairros localizados na porção sul do espaço intra-anel ganham população na década de 1990. Por outro lado, o bairro Centro perde 18\% de sua população na década de 1990. Esse decréscimo populacional também acontece de forma acentuada nos bairros localizados à leste do Centro: Parque Getúlio Vargas (-10\%), Capuchinos (-6\%) e Ponto Central (-20\%).

Via de regra, os bairros que apresentam decréscimo populacional constituem espaços com melhores serviços de coleta de lixo (Figura 3(a)) e pavimentação das ruas (Figura 3(b)), além de melhores médias de renda (Figura 3(c)). A perda de população nesses bairros pode estar associada ao incremento do valor da terra que acaba por induzir a transformação do uso residencial em usos comerciais e de serviços. Esse processo de transformação de usos parece acontecer de forma mais avançada no Centro, que já possui uma população residente muito pequena se comparado ao restante da cidade (ver a área que possui menor concentração de pontos vermelhos na figura 4)

Fonte: Elaborado pelos autores a partir de IBGE 1991 e 2000.

Figura 3 - (a) Domicílios s/ Coleta de Lixo. (b) Qualidade da pavimentação. (c) Rendimento mensal
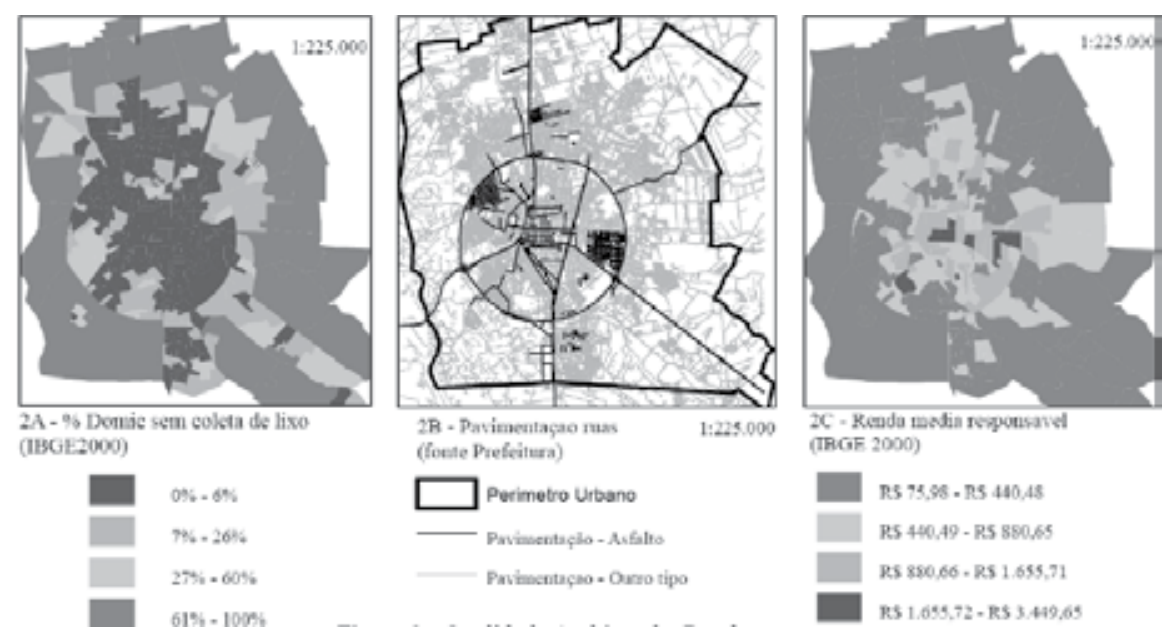

Fonte: Elaborados pelos autores a partir de dados da Prefeitura e IBGE 2000. 
Figura 4 - Distribuição populacional em 2010: 1 ponto $=120$ habitantes



Fonte: Elaborado pelos autores a partir de IBGE 2010.

O decréscimo populacional relativo na zona interna ao anel contrasta com o aumento populacional da zona periférica. Uma grande quantidade de bairros localizados na área externa ao anel de contorno apresenta incremento populacional intenso na década de 1990, superior a 50\% (ver figura 2), o que aponta para a tendência de dispersão urbana. Embora já existam áreas periféricas com altas densidades populacionais (acima de 150hab/ ha ou $1500 \mathrm{hab} / \mathrm{km}^{2}$ ) - localizadas, via de regra, no vetor norte e sul -, uma grande porção do território parcelado fora do anel de contorno ainda apresenta densidades abaixo de $4300 \mathrm{hab} / \mathrm{km}^{2}$ (ver Figura 5).

Figura 5 - Densidade demográfica

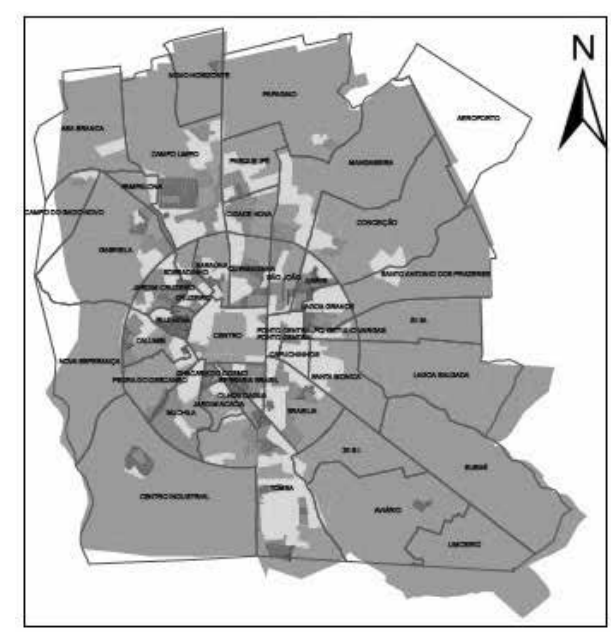

Fonte: Elaborado pelos autores a partir de dados IBGE 2000.

A espacialização dos dados revela ainda que, em Feira de Santana, a tendência de espraiamento urbano parece predominar nas classes de renda inferior, com a ocupação de assentamentos com baixos níveis de infraestrutura e serviços urbanos na periferia. Isso pode ser confirmado na Figura 6 que revela que assentamentos precários concentram-se na área localizada fora do anel de contorno, a qual apresenta maior ritmo de incremento populacional. Assim como o esvaziamento populacional dos bairros adjacentes ao centro, a concentração de assentamentos precários na periferia também pode estar associada ao aumento do valor da terra nos bairros mais bem dotados de serviços.

Figura 6 - Assentamentos Precários em Feira de Santana

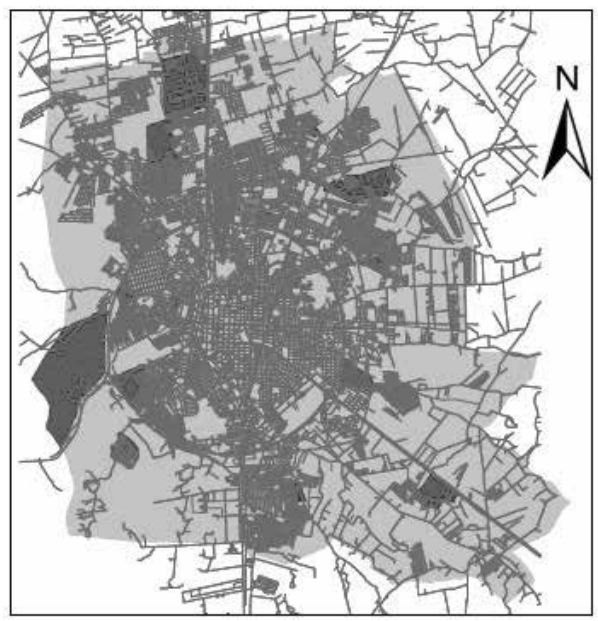

Fonte: Brasil, 2007.

$\mathrm{Na}$ época da construção do sistema que permitiu a elaboração desses cartogramas, os dados censitários de 2010 ainda não haviam sido disponibilizados pelo IBGE, impedindo a análise do incremento populacional de cada bairro no período de 2000 a 2010. Entretanto, a despeito da relativa desatualização dos dados, os cartogramas do período de 1991 a 2000 foram apresentados para um grupo formado por técnicos da administração municipal e por arquitetos da cidade. Em tal evento, refletiu-se a respeito dos efeitos negativos do cenário de descontrole urbanístico e espraiamento urbano presentes no município. De acordo com os técnicos locais, não haveria sinais de alteração, mas apenas de acentuação do fenômeno. A próxima seção busca se debruçar sobre essa hipótese da tendência à acentuação do fenômeno do espraiamento urbano, a partir dos dados dos empreendimentos habitacionais em instalação, no sentido de identificar, comprovar e retratar com a maior precisão possível as tendências futuras de ocupação territorial. 


\section{Cenário futuro: as tendências do processo de parcelamento}

Para esta fase do trabalho, usamos como principal fonte de informações o banco de dados fornecido pela companhia de saneamento local, a EMBASA, tendo em vista que a administração municipal não possui uma base de dados sistematizada a respeito dos loteamentos e dos condomínios aprovados. Esse material abrange todos os 103 parcelamentos (condomínios ou loteamentos) que solicitaram ligações com a rede de abastecimento d'água no período de 2004 a 2009. A espacialização dos dados relativos a esses empreendimentos confirma a tendência de acentuação do fenômeno da dispersão urbana descrito anteriormente e nos leva a várias conclusões sobre as tendências de expansão da malha urbana da cidade.

Figura 7 - Situação dos empreendimentos habitacionais no período de 2004 a 2009

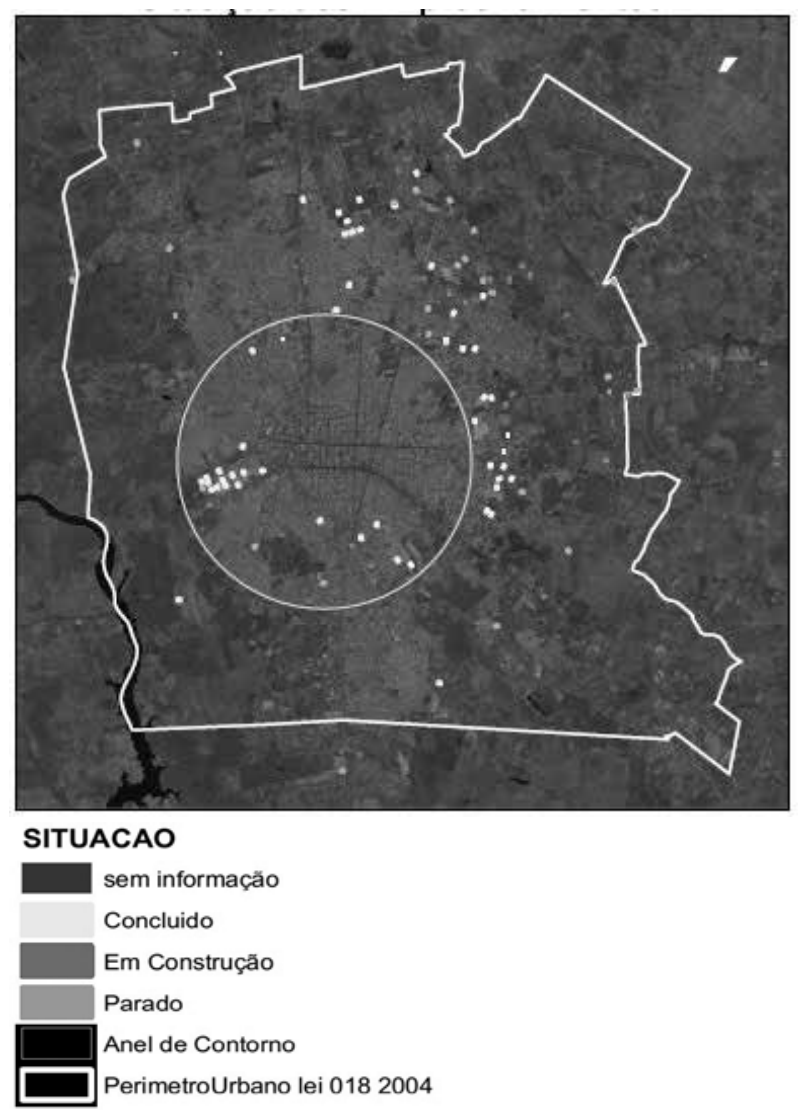

Fonte: Elaboração dos autores a partir de imagem fornecida pela prefeitura municipal, da Lei Municipal nº 018/2004 e dados dos empreendimentos fornecidos pela EMBASA.
A Figura 7 destaca a localização dos empreendimentos e os classifica pela sua situação no processo de implantação da obra. Destaca-se que cerca de $50 \%$ do total da amostra (51 de 103) já está concluído e representa os pontos mais claros na Figura 7. Trata-se de empreendimentos cujos pedidos de viabilidade para expansão da rede se deram no início do período analisado, ou seja, não muito distante do ano de 2004. Esses empreendimentos já executados concentram-se basicamente em 3 regiões: a primeira na região interna ao anel (particularmente no bairro Pedra do Descanso, na porção sudoeste); a segunda, na região imediatamente contígua ao anel na porção leste da cidade (destaca-se o bairro Lagoa Salgada); e uma terceira concentração de empreendimentos que abrange um menor número de caso, na porção norte da cidade, no bairro Parque Ipê, após a Cidade Nova. Por outro lado, os 50 empreendimentos ainda não concluídos, que são mais recentes, estão muito mais dispersos pelo território do que os anteriores, embora haja uma concentração na porção nordeste da cidade, particularmente nos bairros Papagaio, Mangabeira e Conceição.

Outra variável interessante diz respeito à inserção dos empreendimentos com relação à zona efetivamente urbanizada. Do total de 53 empreendimentos concluídos, 39 (74\%) estão dentro de uma faixa de $1,5 \mathrm{~km}$ do anel de contorno. Nos empreendimentos mais recentes, essa relação se inverte, e apenas 16 (32\%) empreendimentos estão dentro dessa faixa, sendo que a maioria dista mais de 1,5 $\mathrm{km}$ do anel de contorno. É importante considerar ainda que nos 16 empreendimentos localizados próximos ao anel, temos 07 empreendimentos contratados pelo programa "Minha Casa, Minha Vida" que estão parados. A partir desses dados, podemos inferir que, nos anos mais recentes, o processo de dispersão urbana se acentua, surge uma tendência de dispersão de empreendimentos habitacionais que se localizam em terrenos distantes da zona efetivamente urbanizada, chegando a extrapolar os limites legais do perímetro urbano da cidade em três casos. 
Figura 8 - Natureza dos empreendimentos habitacionais no período de 2004 a 2009

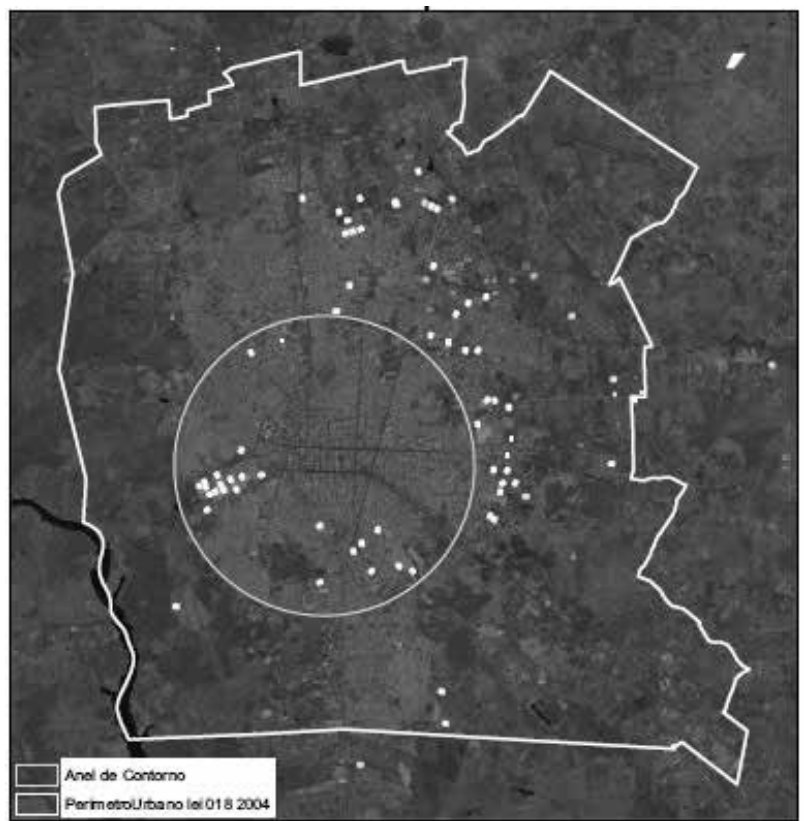

Natureza do Empreendimento

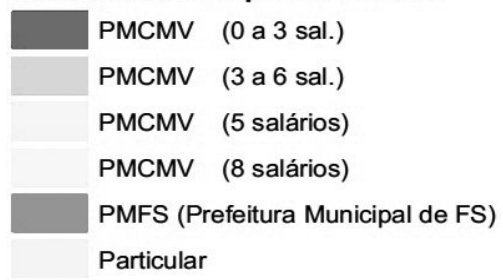

Fonte: Elaboração dos autores a partir de imagem fornecida pela prefeitura municipal, da Lei Municipal no 018/2004 e dados dos empreendimentos fornecidos pela EMBASA.

A Figura 8 destaca a natureza dos empreendimentos habitacionais, ou seja, quais são os empreendimentos resultantes de programas governamentais e quais empreendimentos são particulares. Ela possui ainda informações relativas à faixa de renda do público-alvo dos empreendimentos públicos. Essa figura demonstra com clareza um padrão de localização dos empreendimentos particulares nas áreas mais bem dotadas de serviços urbanos, na região interna ao anel de contorno ou dentro da faixa de 1,5km, com poucas exceções nos bairros $\mathrm{Pa}$ pagaio e Parque Ipê. Por outro lado, no que se refere ao padrão de localização dos empreendimentos públicos, temos uma inversão: a grande maioria dos empreendimentos de iniciativa governamental que contam com algum tipo de financiamento público localiza-se na fronteira da mancha efetivamente urbanizada. Com frequência, encontramos empreendimentos públicos desconectados da cidade propriamente dita. Esse padrão de localização (empreendimentos públicos na periferia e empreendimentos privados na área mais urbanizada) pode ser explicado pelo perfil de renda do público-alvo. Enquanto o mercado imobiliário privado concentra-se nas classes A e $\mathrm{B}$, as classes $\mathrm{C}$ e $\mathrm{D}$ precisam de subsídios do estado para ter acesso à casa própria.

O caso de Feira de Santana nos mostra que os programas governamentais de habitação não têm conseguido inserir as famílias de faixa de renda inferior dentro da cidade propriamente dita. Esse fato possui consequências negativas tanto para a população moradora como para o poder público. No primeiro caso, as classes $\mathrm{C}$ e $\mathrm{D}$ terão dificuldades de acesso aos serviços urbanos básicos. No segundo caso, o poder público precisará de maiores investimentos para expandir as redes de serviços para a periferia. Quando tais investimentos se viabilizarem, eles irão valorizar grande quantidade de terrenos vazios localizados no entorno dos empreendimentos públicos, caracterizando um caso clássico de especulação imobiliária, quando a valorização de investimentos estatais é transferida gratuitamente para proprietários de terras ociosas (CAMPOS FILHO, 1999). Trata-se, portanto, de um processo de urbanização pouco eficiente em termos de racionalização da infraestrutura urbana que está sendo induzido, em grande medida, por empreendimentos que contam com algum tipo de subsídio estatal. O fato de que a fronteira de expansão urbana está sendo aumentada por empreendimentos governamentais sinaliza para uma maior possibilidade de reversão desse quadro, pois o poder público municipal possui maior capacidade de intervir na localização desses empreendimentos.

$\mathrm{Na}$ entrevista com os técnicos da Embasa (Empresa Baiana de Águas e Saneamento S.A.), os entrevistados se mostraram bastante preocupados com a capacidade da rede atual em oferecer um serviço de abastecimento d’água satisfatório para os beneficiários dos empreendimentos do Programa "Minha Casa, Minha Vida" localizados nos bairros Mangabeira e Conceição, na porção nordeste da cidade. Essa questão da capacidade das redes existentes em suportar a população prevista pode ser esclarecida na Figura 9, que classifica os empreendimentos com relação à quantidade de Unidades Habitacionais produzidas. 
Figura 9 - Situação dos empreendimentos habitacionais no período de 2004 a 2009

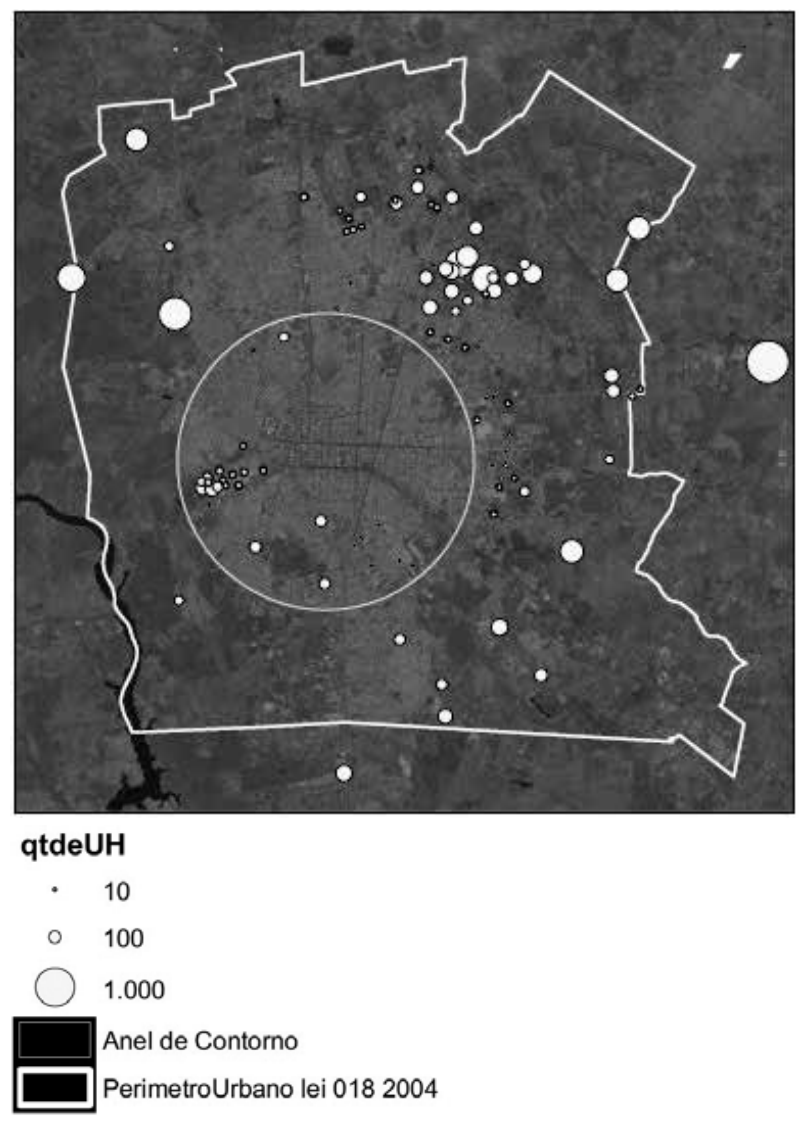

Fonte: Elaboração dos autores a partir de imagem fornecida pela prefeitura municipal, da Lei Municipal nº 018/2004 e dados dos empreendimentos fornecidos pela EMBASA.

A Figura 9 confirma as afirmações dos técnicos da EMBASA ao revelar grande concentração de novas unidades habitacionais sendo construídas na porção nordeste da cidade. Ela revela que uma grande parte dos empreendimentos localizados fora da área efetivamente urbanizada da cidade é de médio e grande porte, ou seja, acima de 100 unidades habitacionais. Isso significa que tais empreendimentos possuem maior capacidade de induzir ao processo de dispersão urbana que se quer evitar. De fato, o empreendimento da incorporadora privada Rodobens Negócios Imobiliários, citado por muitos dos técnicos entrevistados, é o caso mais grave desse processo de dispersão. Trata-se do grande círculo localizado fora do perímetro urbano na porção leste da cidade, ao longo da Avenida Artêmia Pires. Essa avenida se transformou, nos últimos anos, em uma importante artéria de expansão dos condomínios de classes média e alta.

\section{Considerações finais}

Nas cidades brasileiras, o fenômeno de esvaziamento populacional das áreas centrais, e em menor escala dos bairros "nobres”, costuma estar associado à dispersão urbana com a proliferação de condomínios e/ ou loteamentos na periferia, produzindo um tecido urbano descontínuo e pouco econômico. Tal processo tem sido caracterizado como problemático por diversas razões. Em primeiro lugar, os bairros centrais apresentam graves questões de congestionamento viário, pois o uso comercial e de serviços requer um sistema de transporte urbano com uma capacidade superior àquele que foi originalmente construído. A reconstrução representa um gasto adicional para as prefeituras. Em segundo lugar, a monofuncionalidade gera ociosidade dos espaços públicos em horários não comerciais. Em terceiro lugar, o deslocamento do uso habitacional para bairros periféricos gera grande quantidade de viagens centro-periferia nos horários de pico. O crescimento demasiado da periferia obriga ainda o poder público a expandir sua infraestrutura e serviços muitas vezes percorrendo distâncias maiores do que seriam necessárias se o tecido urbano crescesse de forma contínua e compacta. Em Feira de Santana, o espraiamento possui uma consequência negativa adicional, tendo em vista que ela requer a transposição da barreira do anel rodoviário, o que tem acarretado enormes custos ao poder público relacionados às obras de construção de viadutos e passarelas nos inúmeros cruzamentos existentes.

No caso estudado, apesar da percepção generalizada da existência da tendência de espraiamento urbana e de um entendimento desse fenômeno como um problema a ser evitado desde 1992, pouco foi realizado para conter tal processo. Ao contrário, os dados revelam que, no atual contexto de grande volume de recursos para produção habitacional de baixa renda disponível, os empreendimentos financiados com investimentos públicos estão sendo alocados em espaços mais periféricos que a maior parte dos empreendimentos habitacionais privados. A ausência de dados espaciais capazes de dimensionar, quantificar e, sobretudo, retratar o problema em questão, tem contribuído sobremaneira para a perpetuação de um cenário de desconexão entre a real dinâmica urbana e as diretrizes estabelecidas pelos planos urbanísticos. 
Vale ressaltar que o diagnóstico preciso do problema não é suficiente solucioná-lo, mas é condição fundamental para viabilizar politicamente instrumentos capazes de prevenir ou amenizar seus efeitos negativos. $\mathrm{O}$ Estatuto da Cidade traz uma série de instrumentos destinados a conter a tendência de expansão periférica formada por bairros dormitórios predominantemente de baixa renda. Tais instrumentos, como as ZEIS de vazio urbano e o IPTU progressivo no tempo, vão de encontro a uma cultura patrimonialista extremamente arraigada na sociedade brasileira, que não enxerga os efeitos maléficos dos ganhos de capital associados à especulação imobiliária da terra urbana dotada de serviços urbanos. Alterar essa cultura de laisser-faire no processo de uso e ocupação do solo e construir uma nova ordem urbanística brasileira pautada na inclusão territorial passa pela utilização de recursos tecnológicos capazes de retratar com precisão os problemas associados às tendências urbanísticas atuais.

Um desses recursos capazes de contribuir para essa mudança de paradigmas é o Sistema de Informações Geográficas (SIG), pois possui a vantagem de ilustrar as relações espaciais entre as diversas alterações no processo de urbanização, dando subsídios para um processo decisório mais democrático e transparente. Destaca-se ainda a capacidade do SIG de sobrepor espacialmente dados de diversas fontes, aumentando a compreensão dos agentes produtores da cidade a respeito do processo de urbanização.

O uso do SIG impõe um custo infinitamente inferior de tempo e de recursos do que os softwares tipo CAD (Computer Aided Design), tradicionalmente utilizados por arquitetos e gestores urbanos. Os ganhos de produtividade do SIG se devem basicamente por dois aspectos: o uso de sistemas de georreferenciamento e posicionamento absoluto, permitindo a sobreposição de dados de diversas fontes, e a capacidade de espacializar informações tabulares.

\section{Referências}

BAHIA. Lei $n^{\circ}$ 2987/ 2009. Dispõe sobre o enquadramento e delimitação do programa minha casa, minha vida como zonas especiais de interesse social - ZEIS e define os parâmetros urbanos para o programa para a renda de 0 a 3 salários mínimos. Disponível em: <www. camarafeiradesantana.ba.gov.br>. Acesso em: 19 mar. 2013.
BRASIL. Ministério das Cidades. Assentamentos precários no Brasil urbano. 2007. Disponível em: <www.centrodametropole.org.br/mc/assets/pdfs/ assentamentos_web.pdf $>$. Acesso em: 14 fev. 2011.

BRASIL. Lei $n^{\circ} 10.257$, de 10 de julho de 2001. Estatuto da Cidade. Disponível em: <http://www.planalto.gov. br/ccivil_03 /leis/leis_2001/110257.htm>. Acesso em: 19 mar. 2013.

CAMPOS FILHO, C. M. Cidades brasileiras: seu controle ou o caos. São Paulo: Studio Nobel, 1999.

CUNHA, E.; ERBA, D. (Org). Manual de Apoio CTM: diretrizes para a criação, instituição e atualização do cadastro territorial multifinalitário nos municípios brasileiros. Brasília: Ministério das Cidades, 2010.

\section{EMPRESA BAIANA DE SANEAMENTO E} ABASTECIMENTO. Banco de dados: demonstrativo da situação dos empreendimentos do período 2004-2009 no SLAA. Feira de Santana, 2011. No prelo.

FEIRA DE SANTANA, Prefeitura Municipal. Malha viária da área urbana, formato DXF, obtida a partir de restituição aerofotogramétrica de imagem aérea de1998. CDROM.

INSTITUTO BRASILEIRO DE GEOGRAFIA E ESTATÍSTICA. Censo 2010 (resultados preliminares). Disponível em: <http://www.ibge.gov.b r/home/ estatistica/populacao/censo $2010 /$ resultados preliminares_amostra/notas_resultados_preliminares_ amostra.pdf >. Acesso em: 19 mar. 2013.

INSTITUTO BRASILEIRO DE GEOGRAFIA E ESTATÍSTICA. Censo demográfico 1991. Disponível em: < http://www.ibge.gov.br/home/estatistica/populacao/cen sodem/default_censo1991.shtm>. Acesso em: 19 mar. 2013.

INSTITUTO BRASILEIRO DE GEOGRAFIA E ESTATÍSTICA. Censo demográfico 2000. Disponível em: $<$ http://www.ibge.gov.br/home/estatística/populacao/ censo2000/>. Acesso em: 19 mar. 2013.

PEREIRA, G. C.; SILVA, B. C. N. Geoprocessamento e Urbanismo. In: GERARDI, Lucia Helena de Oliveira; MENDES, Iandara Alves. (Org.). Teoria, técnicas, espaços $e$ atividades: temas de geografia contemporânea. Rio Claro: Programa de Pós-Graduação em Geografia UNESP; AGETEO, 2001.

SANTOS JUNIOR, O. A. dos; MONTANDON, D. T. (Org). Os planos diretores municipais pós estatuto da cidade: balanço crítico e perspectivas. Rio de Janeiro: Observatório das Cidades: IPPUR/UFRJ, 2011. 
SOUZA, M. L. de. Mudar a cidade: uma introdução crítica ao planejamento e à gestão urbanos. 3. ed. Rio de Janeiro: Bertrand Brasil, 2004. 
Para publicar na revista Universitas: Arquitetura e Comunicação Social, acesse 0 endereço eletrônico www.publicacoesacademicas.uniceub.br. Observe as normas de publicação, para facilitar e agilizar o trabalho de edição. 